\title{
An Interactive Content Development for Depression Awareness among Tertiary Students
}

\author{
Sarni Suhaila Rahim, Thum Wei Ching \\ Faculty of Information and Communication Technology \\ Universiti Teknikal Malaysia Melaka \\ Hang Tuah Jaya, 76100 Durian Tunggal, Melaka, Malaysia
}

\begin{abstract}
D Animation: Depression among Tertiary Students" is a novel interactive content development that gives information of depression to public. It consists of seven modules of depression which are Introduction, Statistics, Types, Symptoms, Causes, Treatments and Video of Depression Information. The objectives of this project are to study the causes and effects of depression among tertiary-level students in Malaysia, to design and develop a 2D animation in raising awareness about depression to the viewers and to investigate the effectiveness of depression animation to the users. The methodology used for this project is Multimedia Production Process which consists of three stages which are pre-production, production and post-production. The testing result shows that the interactive content for depression animation is accepted and effective to the public in order to have a better understanding and awareness on depression among tertiary students.
\end{abstract}

Keywords-2D animation; awareness; depression; interactive content; tertiary students

\section{INTRODUCTION}

Tertiary students are those pursuing tertiary level of education which includes diploma, bachelor's, masters and doctoral degrees after their secondary level of education. Attending colleges or universities seems challenging and stressful for tertiary students. They have to cope with academic pressure, future worries, independent living from parents, family responsibilities, social life and so on. In order to handle all kind of factors in a perfect manner, tertiary students are having depression. Depression is the most common psychological problems among tertiary students [1]. According to statistics from the 2015 National Health and Morbidity Survey (NHMS), 29.2 percent, or 4.2 million, citizens above the age of 16 years suffer from depression. The study in [2] reviews the number of cases had doubled compared to 2006 (11.2 percent) and 1996 (10.6 percent).

Depression is a common mental disorder, characterized by prolonged sadness, loss of interest, feeling of guilt or worthless, disturbed sleep or appetite, feelings of tiredness, and poor concentration [3]. It is a serious medical illness that negatively affects one's feeling, thinking and behaving. This mental disorder will decrease a person's performance at work and at home [4]. Globally, more than 300 million people of all ages are now living with depression, an increase of depression more than $18 \%$ between 2005 and 2015 [5]. Based on statistics, there are $40 \%$ of Malaysian suffer from depression [6]. Depression will lead to inclination to suicidal acts. According to World Health Organization, there are nearly 800,000 people die due to suicide every year [7]. Therefore, suicide is the second leading cause of death due to depression among 15-29 years old.

This project aims to create a $2 \mathrm{D}$ animation on depression among tertiary students. There is a lack of depression awareness campaign. Information or knowledge on depression is limited among students. In addition, causes and effects of depression needed to be identified. The World Health Organization estimates that by 2020 depression will be the leading cause of disability globally. In addition, Ministry of Health Malaysia provides statistics that show a worsening state of depression among students, that is from one in ten individuals in 2011 to one in five in 2016 [8]. Students are facing independent living challenges as well as educational challenges. According to Kumaraswamy [9], depression among tertiary-level students has become a concerning issue as students are the human capital of society. Students may suffer from Schizophrenia and inclines to suicide if the depression state is prolonged [8]. University students are having cursory knowledge of depression and giving negative attitudes towards depression [10]. According to Nam et al., [11], stigma can be reduced and help-seeking can be increased by improving public understanding of depression and suicide. Therefore, public awareness and understanding have to be raised before the worsening state of depression among tertiary students.

The objectives of this project are to study the causes and effects of depression among tertiary-level students in Malaysia, to design and develop a $2 \mathrm{D}$ animation in raising awareness about depression to the viewers and finally to investigate the effectiveness of the depression animation to the users. Target users of this project is university and college students. The modules of this project are Introduction of Depression, Statistics of Depression, Types of Depression, signs and Symptoms of Depression, Causes of Depression, Treatments of Depression and Video of Depression. Methodology used for this project is Multimedia Production Process which consists of three stages which are pre-production, production and postproduction. The software used to create this project are Adobe Audition, Adobe Animate, Adobe Photoshop, Adobe Illustrator and Vegas Pro. The outcome of this project is the 2D animation for depression which aims to give public awareness and understanding.

This paper is organized as follows. Section 2 presents previous related work on $2 \mathrm{D}$ animation and depression. Section 3 describes in details the overall methodology of this research, while Section 4 presents the developed system testing and 
results. The discussion of the research project is presented in Section 5. Finally, Section 6 presents some conclusions and future work.

\section{LITERATURE REVIEW}

Animation is used to create multimedia and gaming products by designing, drawing, making layouts and preparation of photographic sequences. An animation is the illusion of movement created by rapid display of images in sequence [12]. Efficiency is one of the 2D animation benefits. Design of 2D animation is less complex and simpler than in 3D animation. Two-dimensional is being chosen for the case that the message is needed to be highlighted. In addition, costeffectiveness is the other benefit of 2D animation. The simplicity and efficiency of this animation can meet customer needs and also budget constraints, besides artistic freedom. Interactive animation lets the users join on more levels than just-viewing and better than non-interactive animation as it gives better conversion. It can convey the target message efficiently. Furthermore, there is a better engagement as users can decide what they want to watch or to skip. This type of animation is more attractive, compelling and convincing that brings higher responses.

This project will focus on the depression among tertiary students. The use of 2D animation can convey the message and information regarding depression and its treatments to target audiences in order to raise awareness and understanding of depression among them. The signs or symptoms of depression among students can be recognized earlier and proper treatments can be offered before it is too late. An interactive of 2D animation provides interaction with its users by giving control to users on information accessibility through menu which consists of introduction, statistics, types, symptoms, treatments of depression and video.

There are three existing systems found to compare with this project, which are a video named "Depression Motion Graphic Awareness Campaign" and two 2D animation named "Depression \& Anxiety Awareness Video" and "What is Depression". Table I shows the comparison of these existing systems.

Fig. 1 shows the screenshot of the first existing system, "Depression Motion Graphic Awareness Campaign". It is a 1 minute and 50 seconds video about depression awareness campaign that posted on Youtube. This video portrays information about depression definition, statistics and the way to overcome it. Meanwhile, Fig. 2 shows the screenshot of the second existing system. It is a 3 minutes and 52 seconds $2 \mathrm{D}$ animation that posted on Youtube. This animation portrays information about symptoms of depression and its treatments to increase awareness depression and anxiety in urban low income societies in Pakistan. Finally, Fig. 3 shows the screenshot of the "What is Depression" animation. This is a 4 minutes and 28 seconds 2D animation about what is depression that posted on Youtube. This animation portrays information about symptoms of depression and its treatments to help those suffered from depression.

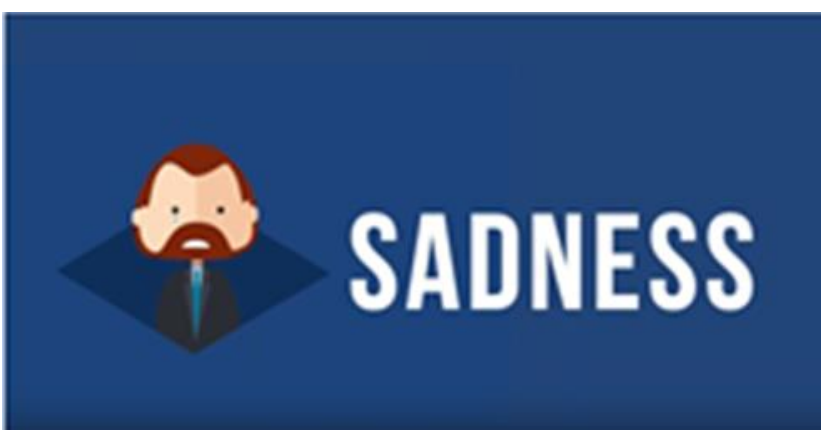

Fig. 1. Screenshot of Depression Motion Graphic Awareness Campaign [13]

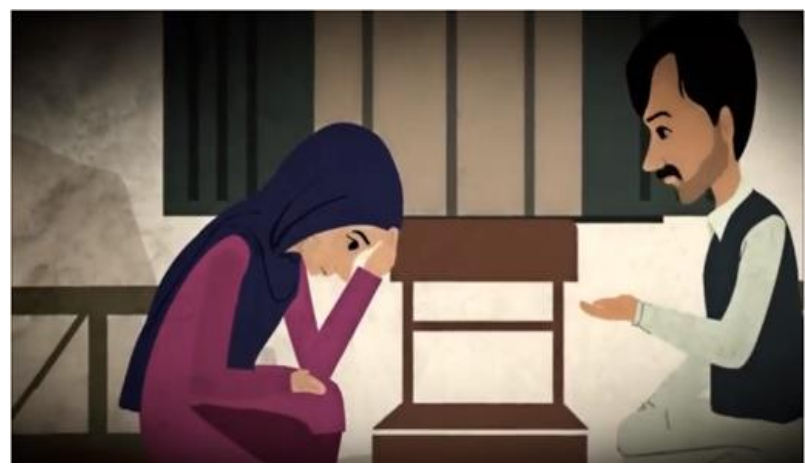

Fig. 2. Screenshot of Depression Motion Graphic Awareness Campaign [14]

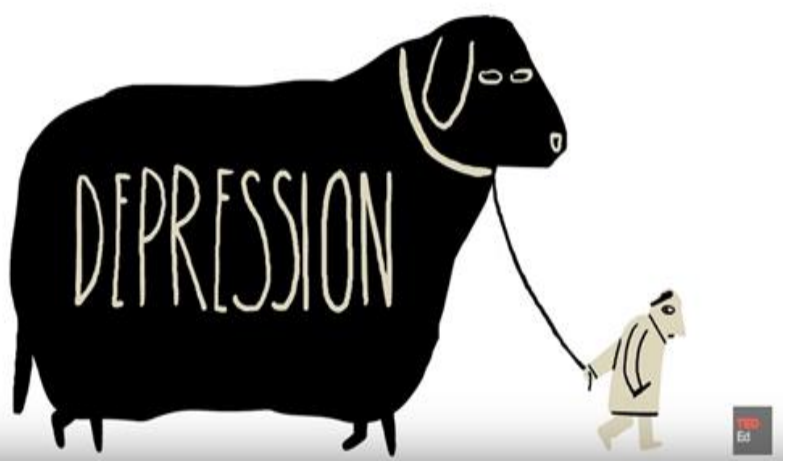

Fig. 3. Screenshot of Depression Motion Graphic Awareness Campaign [15]

Based on Table I, it can be concluded that there is no user interaction in these three existing systems as they are video and 2D animation. Most of these systems are less attractive because they have fewer multimedia elements, which two of the systems consist of four types of multimedia elements only like graphic, audio, video, animation or text. All of these systems are lack of user interaction and interactivity because these systems do not have interactive button for users to control the information or graphics that they want to view or skip. The three existing systems have covered different type of modules such as definition of depression, statistics, symptoms of depression and its treatments. However, these existing systems do not offer an interactive content development for depression. The developed project presents a novel interactive content for depression among tertiary students, besides novel content verification and a new video on depression information by the Counsellor. 
TABLE I. COMPARISON OF EXISTING SYSTEMS

\begin{tabular}{|c|c|c|c|}
\hline $\begin{array}{l}\text { Title } \\
\text { Features }\end{array}$ & $\begin{array}{l}\text { Depression } \\
\text { Motion } \\
\text { Graphic } \\
\text { Awareness } \\
\text { Campaign } \\
\text { [13] }\end{array}$ & $\begin{array}{l}\text { Depression } \\
\text { \& Anxiety } \\
\text { Awareness } \\
\text { Video [14] }\end{array}$ & $\begin{array}{l}\text { What is } \\
\text { depression? [15] }\end{array}$ \\
\hline Content & $\begin{array}{l}\text { Depression } \\
\text { definition, } \\
\text { statistics and } \\
\text { treatments }\end{array}$ & $\begin{array}{l}\text { Symptoms of } \\
\text { depression and } \\
\text { its treatments }\end{array}$ & $\begin{array}{l}\text { Symptoms of } \\
\text { depression and its } \\
\text { treatments }\end{array}$ \\
\hline $\begin{array}{l}\text { Attraction } \\
\text { Level }\end{array}$ & Less attractive & Less attractive & Attractive \\
\hline Type & Video & 2D Animation & 2D Animation \\
\hline Format & Mp4 & Mp4 & Mp4 \\
\hline Target User & Public & Public & Public \\
\hline Interactivity & No & No & No \\
\hline $\begin{array}{l}\text { User } \\
\text { interaction }\end{array}$ & No & No & No \\
\hline $\begin{array}{l}\text { Duration } \\
\text { (minutes) }\end{array}$ & $1: 50$ & $3: 52$ & $4: 28$ \\
\hline Language & English & English & English \\
\hline $\begin{array}{l}\text { Interactive } \\
\text { button }\end{array}$ & No & No & No \\
\hline $\begin{array}{l}\text { Multimedia } \\
\text { Element }\end{array}$ & $\begin{array}{l}\text { Text } \\
\text { Graphic } \\
\text { Audio } \\
\text { Video }\end{array}$ & $\begin{array}{l}\text { Graphic } \\
\text { Audio } \\
\text { Video } \\
\text { Animation }\end{array}$ & $\begin{array}{l}\text { Text } \\
\text { Graphic } \\
\text { Audio } \\
\text { Video } \\
\text { Animation }\end{array}$ \\
\hline
\end{tabular}

\section{METHODOLOGY}

The methodology used in this project is Multimedia Production Process, consists of three main phases, which are pre-production, production and post-production. There are six phases involved in these three main phases, which are analysis, design, implementation, testing, evaluation and publishing. In this section, all requirements will be further analysed in detail.

\section{A. Analysis}

In order to gather important information which is the content of the project, an interview session is conducted. In addition, online questionnaire is distributed to 80 respondents which are tertiary students in Malaysia in order to get feedback from public about depression.

\section{1) Interview Session with Counsellor}

The data are collected through the interview session with the Counsellor at Universiti Teknikal Malaysia Melaka (UTeM) Counselling Unit. Table II shows the details of data collection process.
TABLE II. CONTENT VERIFICATION

\begin{tabular}{|l|l|}
\hline Verification & Subject Matter Expert \\
\hline Contents for six modules & UTeM Counsellor \\
\hline $\begin{array}{l}\text { Video on common questions about } \\
\text { depression }\end{array}$ & UTeM Counsellor \\
\hline $\begin{array}{l}\text { Justification of five selected types of } \\
\text { depression }\end{array}$ & UTeM Counsellor \\
\hline
\end{tabular}

\section{2) Public Online Survey}

Besides the interview session, the data are collected through the online survey by using Google Form. The questionnaire is divided into four sections, which are demographic, causes, symptoms and treatments. There are 12 questions included in this questionnaire. The aim of this survey is to study about the prevalence of depression among tertiary students, including symptoms, causes and treatments of depression. Most of the respondents are female aged from 2025 years old who are undergraduate students. Fig. 4 to Fig. 7 show the findings of the survey. Results are presented and analysed as below.

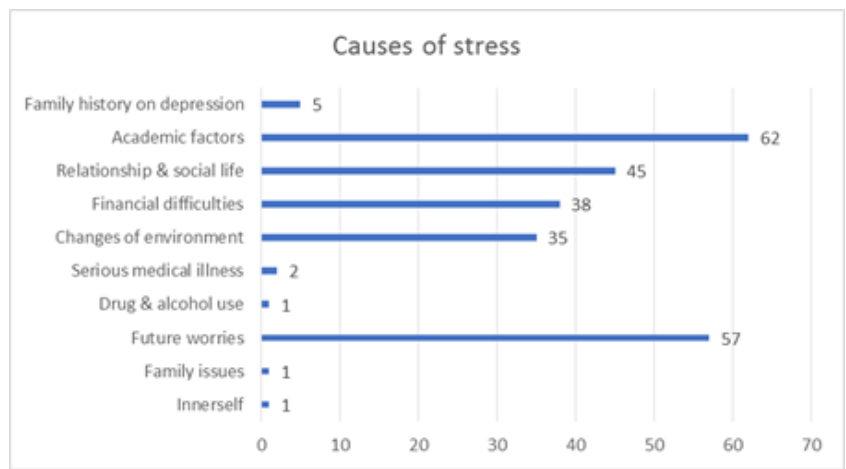

Fig. 4. Causes of stress

Fig. 4 shows academic factors, future worries and relationship and social life are among the factors that bring stress to students representing of $77.5 \%$ (62 counts), $71.3 \%$ (57 counts) and $56.3 \%$ (57 counts) respectively. These followed by $47.5 \%$ (38 counts) of financial difficulties and $43.8 \%$ (35 counts) of changes of environment factor.

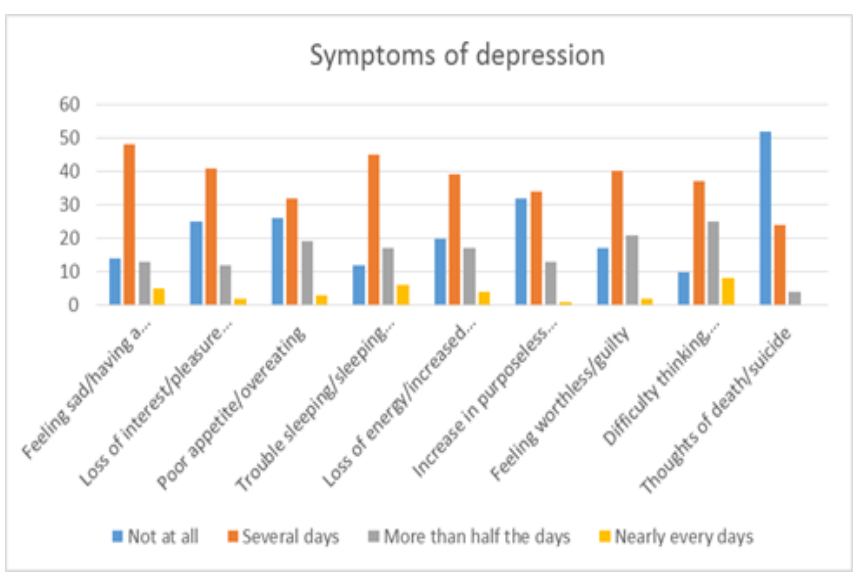

Fig. 5. Symptoms of depression 
Fig. 5 shows the result of symptoms of depression faced by the students. Students that choose the option of more than half days and nearly every days might be having depression. Overall, most of the students select option of several days for all symptoms of depression except for thought of suicide. From this result, it reveals that students might just having stress with difficulty in study, relationship factors and so on. In contrast, there are students who choose option of more than half days and nearly every days. For option more than half days, students select difficulty thinking, feeling worthless and poor appetite or overeating the most among other symptoms whereas for option nearly every day, students choose difficult thinking, trouble sleeping and feeling sad the most. By comparing these two options, students are facing difficulty thinking for the symptoms of depression.

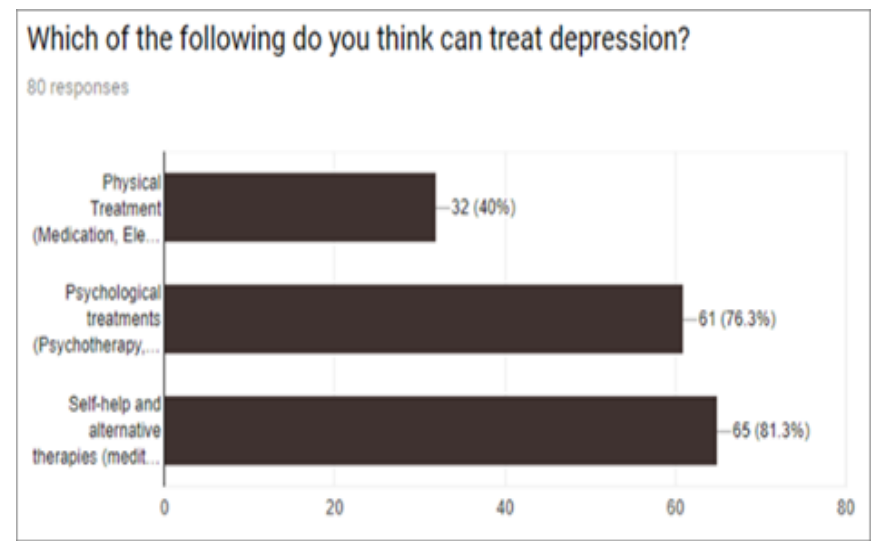

Fig. 6. Treatments of depression

Fig. 6 shows the treatments of depression performed by the students. It presents the highest treatment is self-help and alternative therapies which is $81.3 \%$ followed by $76.3 \%$ of psychological treatments. The lowest treatment selected is the physical treatment which is $40 \%$.

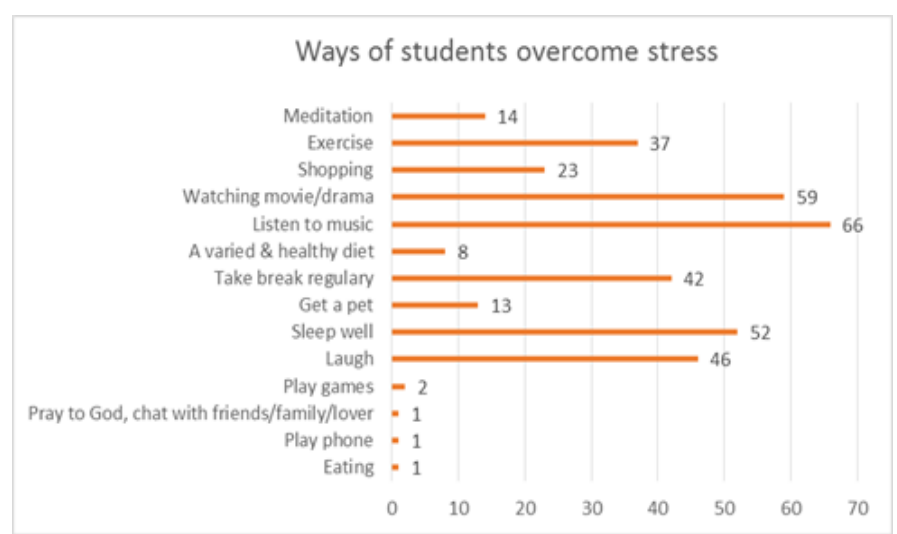

Fig. 7. Ways of students overcome stress

Fig. 7 shows most of the students handle their stress by listening music which is $82.5 \%$. This is followed by watching movie or drama, sleep well, laugh and take break regularly which are $73.8 \%, 65 \%, 57.5 \%$ and $52.5 \%$ respectively.

In conclusion, academic factor, difficulty thinking and selfhelp and alternative therapies are the main causes, symptoms and treatments of depression of 80 respondents respectively.
As most of the students are undergraduate students ranged between 20 to 25 years old, they are facing a lot of challenges and difficulty in their studies. They have to study hard to achieve better results. Therefore, they are facing depression when they cannot cope with their studies which leads to difficulty in thinking nearly everyday. Most of them prefer self-help and alternative therapies like listening to music.

\section{B. Design}

During the design phase, the project is designed to satisfy the requirements that identified in the previous analysis phase. In this phase, it takes time to finish all the design for the 2D animation such as the menu, layout, interactive buttons and interactive elements. During this phase also, the storyboard of the design and character profile are performed. Fig. 8 to Fig. 11 show some of the interfaces of this project.

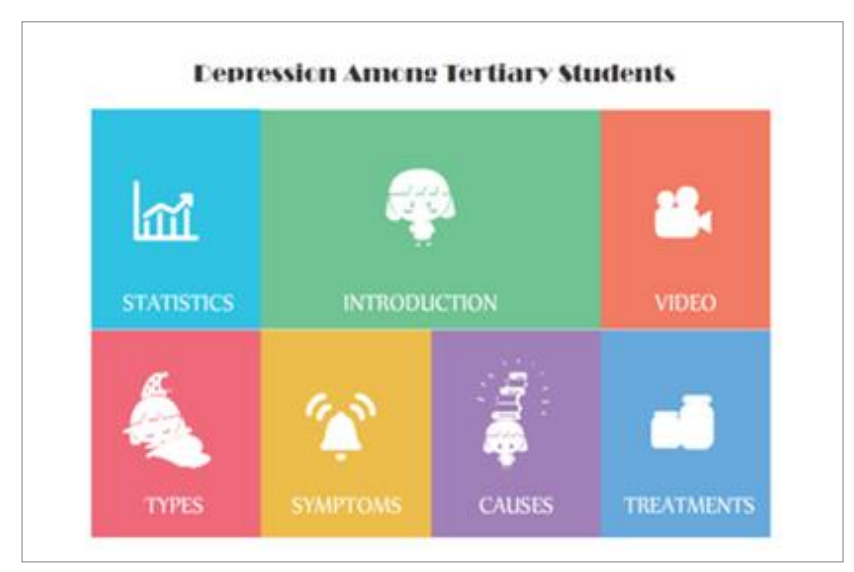

Fig. 8. Interface of main menu

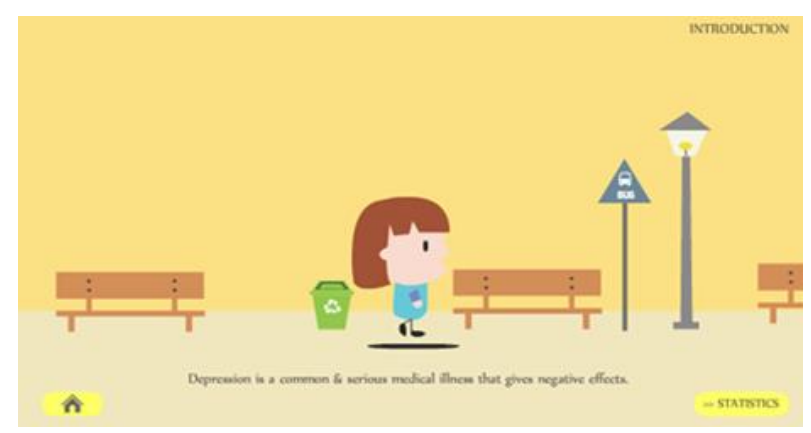

Fig. 9. Interface of Introduction module

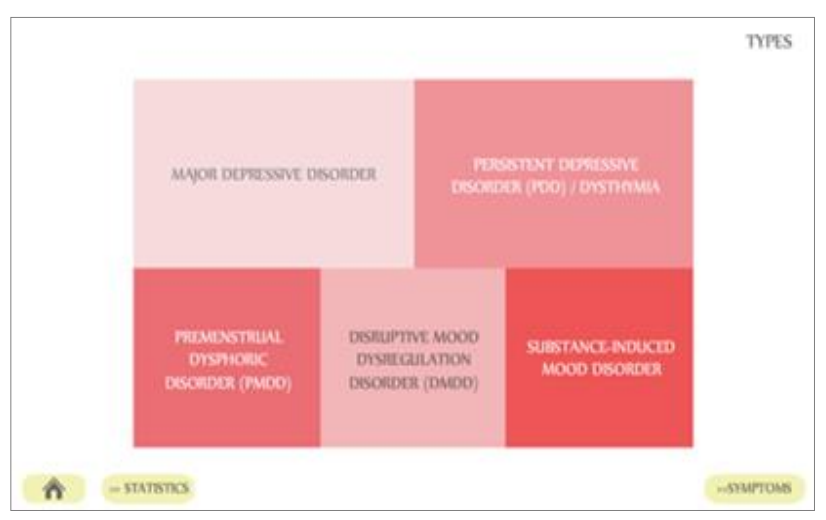

Fig. 10. Interface of Types of Depession module 


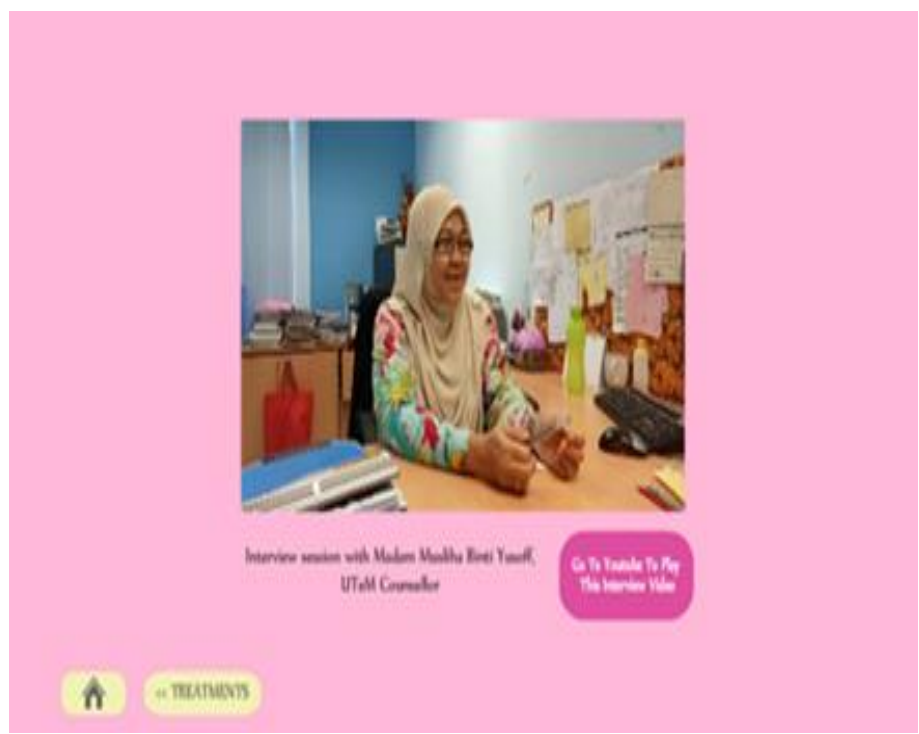

Fig. 11. Interface of Video Depression Information module

\section{Development}

Text is used to give information and explanation of each of the modules. The font of the text used for title of home page and title of menu page are Berlin Sans FB and Broadway respectively. The font of text used for title of menu, subtitle and title of button are Nyala.

The graphics or images used in this project are in Portable Network Graphic (PNG) format and JPEG format. All of the images are vector images in $2 \mathrm{D}$ form. Those vector images have been drawn and edited by using Adobe Illustrator CS6. Then, those designed and edited images will imported to Adobe Animate for animate purposes.

The audio is recorded by using voice recording equipment and then cleaned and edited in Adobe Audition. Another source of sound effect is obtained from internet. Royalty free sound effect were acquired from Freesound.

The interview video on depression among tertiary students with the Counsellor has been edited by using Vegas Pro. The video effects used in this video are film dissolve and dither dissolve. The video duration is about 3 minutes and 26 seconds and it is exported in MP4 format. The integration process was done by using Adobe Animate. All the multimedia elements created were arranged according to modules in Adobe Animate. The final product was exported as SWF file. Fig. 12 shows the process of media integration for this project.

\section{Testing}

This section discusses the testing on the product of the project, focusing on the aspects proposed in the project objective. The testing aims to achieve the third objective of this project, which is to investigate the effectiveness of the depression animation to the users.

Test plan is used to determine the test user, test environment and the test schedule that will be carried out for this project.

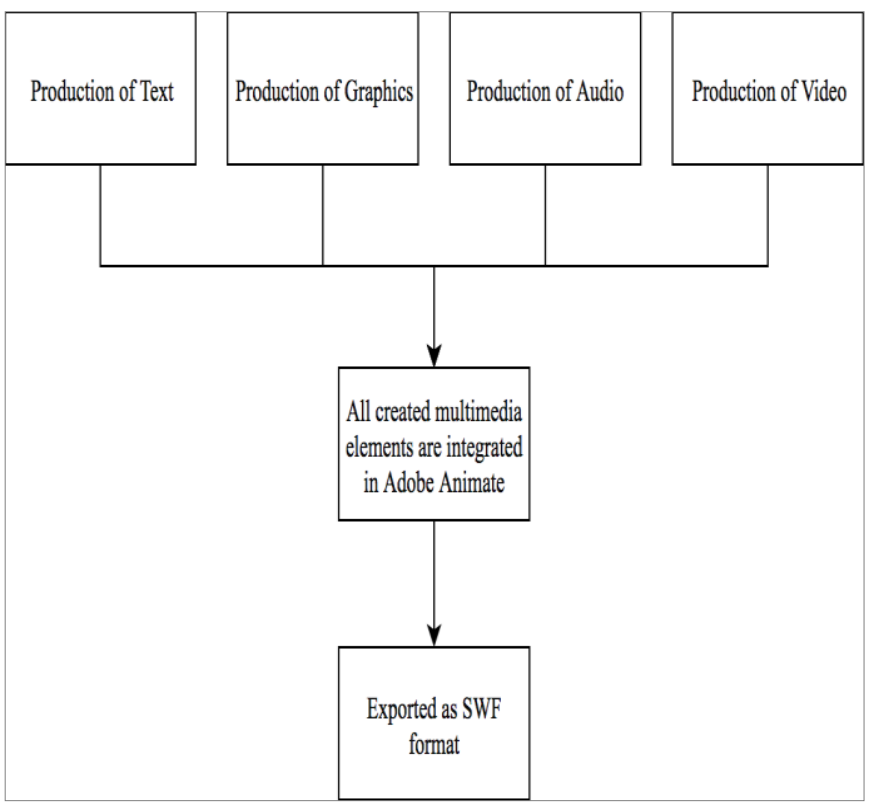

Fig. 12. Process of media creation

\section{3) Test User and Test Environment}

Table III shows the details of the users and venue involved.

TABLE III. TEST USER AND ENVIRONMENT

\begin{tabular}{|l|l|l|}
\hline User & Environment & Total \\
\hline Counsellors & UTeM Counselling Unit & 2 \\
\hline Multimedia Experts & FTMK, UTeM & 5 \\
\hline Tertiary Students & Online Testing & 70 \\
\hline
\end{tabular}

\section{4) Test Schedule for Target User}

Test schedule describes method used for testing, the number of questions, total respondents, date and venue. The method used for testing in this project is questionnaire. Table IV, Table V and Table VI show the schedule of testing among the counsellors, multimedia experts and tertiary students, respectively

TABLE IV. TEST SCHEDULE FOR COUNSELLOR

\begin{tabular}{|c|c|c|c|}
\hline \multicolumn{4}{|c|}{ Target User: Counsellors } \\
\hline $\begin{array}{l}\text { Method: } \\
\text { Questionnaire }\end{array}$ & $\begin{array}{l}\text { Number of } \\
\text { Question }\end{array}$ & $\begin{array}{l}\text { Total } \\
\text { Respondents }\end{array}$ & Date and Venue \\
\hline Content & 5 & 2 & \multirow{3}{*}{$\begin{array}{l}4 / 7 / 2018 \\
10 \mathrm{am}-11 \mathrm{am} \text { at } \\
\text { UTeM } \\
\text { Counselling Unit }\end{array}$} \\
\hline Other & 5 & & \\
\hline Total & 10 & 2 & \\
\hline
\end{tabular}

TABLE V. TEST SCHEDULE FOR MULTIMEDIA EXPERTS

\begin{tabular}{|l|l|l|l|}
\hline \multicolumn{3}{|l|}{ Target User: Multimedia Experts } \\
\cline { 1 - 2 } $\begin{array}{l}\text { Method: } \\
\text { Questionnaire }\end{array}$ & $\begin{array}{l}\text { Number of } \\
\text { Question }\end{array}$ & $\begin{array}{l}\text { Total } \\
\text { Respondents }\end{array}$ & Date and Venue \\
\hline $\begin{array}{l}\text { Functionality } \\
\text { Testing }\end{array}$ & 6 & 5 & $\begin{array}{l}4 / 7 / 2018- \\
18 / 7 / 2018\end{array}$ \\
\cline { 1 - 2 } $\begin{array}{l}\text { Usability } \\
\text { Testing }\end{array}$ & 6 & $\begin{array}{l}\text { FTMK, UTeM } \\
\text { FTM }\end{array}$ \\
\cline { 1 - 2 } $\begin{array}{l}\text { User Interface } \\
\text { Testing }\end{array}$ & 6 & 5 & \\
\hline Total & 18 & 5 & \\
\hline
\end{tabular}


TABLE VI. TEST SCHEDULE FOR TERTIARY STUDENTS

\begin{tabular}{|l|l|l|l|}
\hline Target User: Tertiary Students \\
\cline { 1 - 3 } $\begin{array}{l}\text { Method: } \\
\text { Questionnaire }\end{array}$ & $\begin{array}{l}\text { Number of } \\
\text { Question }\end{array}$ & $\begin{array}{l}\text { Total } \\
\text { Respondents }\end{array}$ & $\begin{array}{l}\text { Date and } \\
\text { Venue }\end{array}$ \\
\hline Content & 10 & 70 & $4 / 7 / 2018-$ \\
Total & 10 & 70 & $\begin{array}{l}11 / 7 / 2018 \\
\text { via online } \\
\text { Google Form }\end{array}$ \\
\hline
\end{tabular}

\section{Test Result And AnALysis}

The test result and analysis have been generated into different types of graphical representation for easy analysis of the result.

\section{1) Test Result for Counsellors at UTeM Counselling Unit}

Table VII shows Question 1 to Question 5 for the Counsellors at UTeM Counselling Unit focusing on the contents of the application. Meanwhile, Fig. 13 shows result of content (Question 1 to Question 5) from two respondents who are Psychology Officer at UTeM Counselling Unit.

TABLE VII. QUESTION FOR COUNSELLOR (CONTENT)

\begin{tabular}{|l|}
\hline Question for Contents \\
\hline Question 1: The information provided is valid and correct. \\
\hline $\begin{array}{l}\text { Question 2: The information provided is sufficient for public } \\
\text { knowledge. }\end{array}$ \\
\hline $\begin{array}{l}\text { Question 3: The explanation of each module is clear and easy to } \\
\text { understand. }\end{array}$ \\
\hline Question 4: The interview video for depression is clear and correct. \\
\hline $\begin{array}{l}\text { Question 5: This project can help public know more about depression } \\
\text { and raise their awareness towards depression }\end{array}$ \\
\hline
\end{tabular}

TABLE VIII. QUESTION FOR COUNSELLOR (OTHER FEATURES)

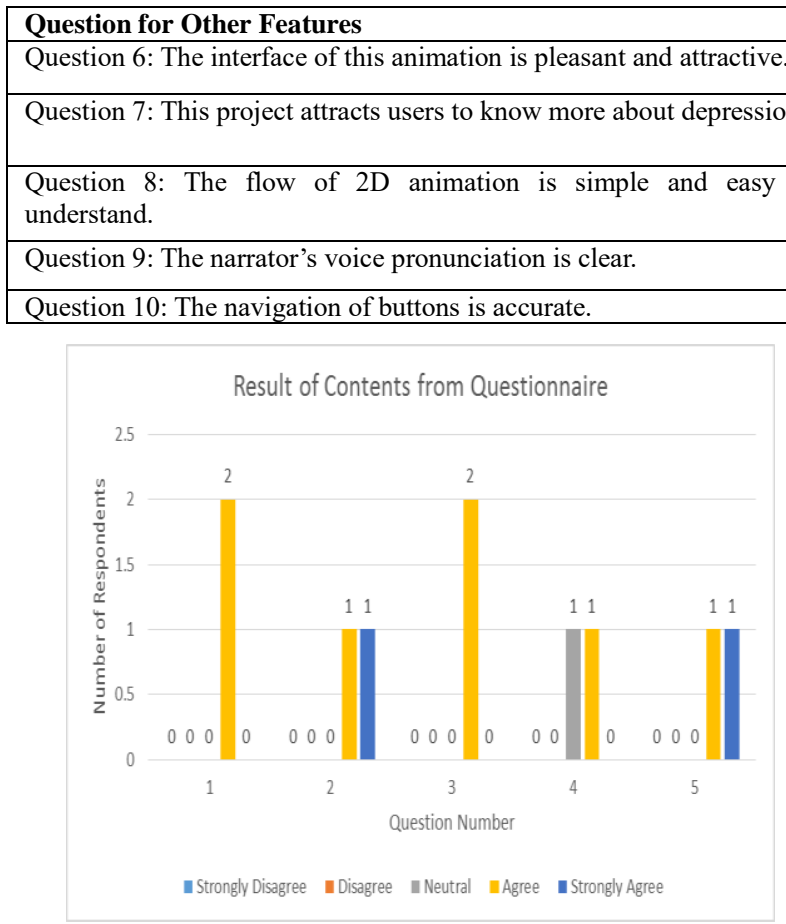

Fig. 13. Result of Contents from Questionnaire
Based on the results presented in Fig. 13, it can be concluded that all of the respondents agree that all of the information provided is valid and correct. For Question 2, one of the respondents strongly agree for this question, while another respondent agree and may has an opinion that more information can be added. Moreover, all of the respondents agree that the explanation of each modules is clear and easy to understand. This is because they think that explanation of each modules can be more clear and easy to understand in order to make this project interesting. For Question 4, one of the respondents agree that interview video for depression is clear and correct, whereas another respondent chooses neutral for this question. Overall, both of the respondents have a thought that the interview video can be improved to be clearer and correct. Finally, for Question 5, one of the respondents strongly agree while another respondent agree that this project can help public know more about depression and raise their awareness towards depression.

There are another five questions, which are Question 6 to Question 10, representing questions on the other features of the application. Table VIII shows the Question 5 to Question 10, while the results from these questions are presented in Fig. 14.

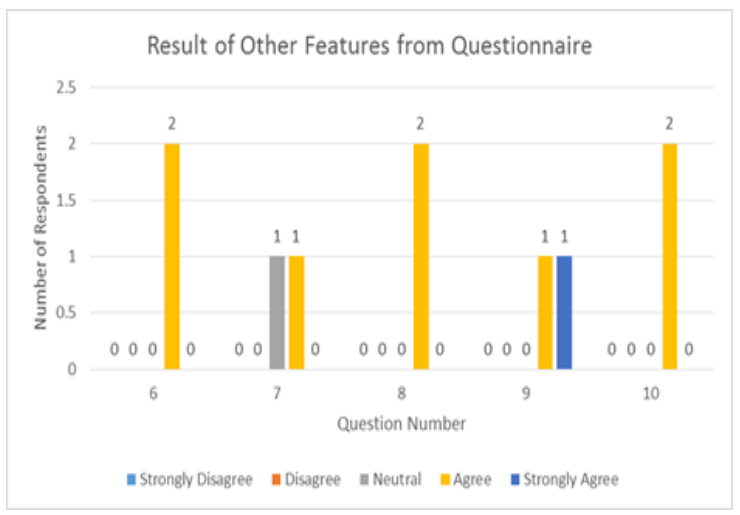

Fig. 14. Result of Other Features from Questionnaire

Fig. 14 shows that all of the respondents agree that the interface of this animation is pleasant and attractive. They think that the interface of this animation is pleasant and attractive, however the interface can be improved to be better.

Meanwhile, for Question 7, one of the respondent agree that this project attracts users to know more about depression whereas another respondent chooses neutral. Based on Fig. 14, both of the respondents have an opinion that this project can be more attractive in order to attract users to know more about depression. For Question 8, it shows that all of respondents agree that the flow of $2 \mathrm{D}$ animation is simple and easy to understand. The flow of this project is good and understandable to its users. One respondent strongly agree for Question 9 that the narrator's voice pronunciation is clear, while the other one agree to this question. For Question 10, it shows that all of the respondents agree for this question. They think that the navigation of the buttons are accurate but the navigation of buttons still can be improved.

2) Test Result for Multimedia Experts at Faculty of Information and Communication Technology (FTMK), UTeM 
The testing for multimedia experts focusing on three parts, which are functionality, usability and user interface. Table IX shows the functionality test questions, while the result of these questios can be referred in Fig. 15.

TABLE IX. FUNCTIONALITY TESTING QUESTION

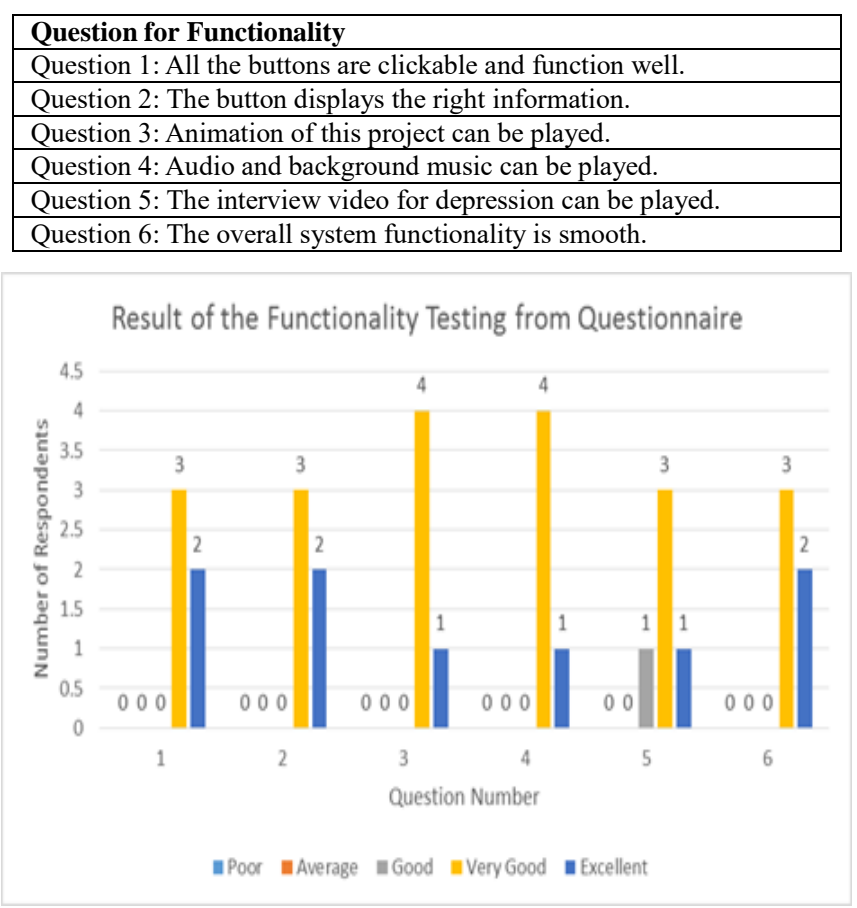

Fig. 15. Result of Functionality Testing from Questionnaire

Fig. 15 shows the result of the functionality testing from questionnaire filled by four multimedia experts. For Question 1, it reveals that all the buttons are clickable and function well

where two out of 5 respondents choose excellent for this question whereas 3 out of 5 respondents choose very good. For Question 2 which is about the button displays the right information, out of 5 respondents, two multimedia experts choose excellent as their answer, whereas 3 out of 5 respondents choose very good. This shows that the button displays the information rightly. For Question 3 which asking that animation of this project can be played, most of the respondents choose very good for this question whereas one of the respondents choose excellent. It shows that the animation of this project can be played smoothly. Question 4 asking about the audio and background music, majority of the respondents choose very good as their answer while only one respondent choose excellent as his or her answer. They agree that audio and background music can be played smoothly and nicely. Most of the respondents choose very good for Question 5 as they think that the interview video for depression can be played. Only two of the respondents choose excellent and neutral, respectively. One of them may have an opinion that the interview video for depression can be played well whereas another respondent may think that improvement for the video can be made. Finally, Question 6 focusing on the overall system functionality. Majority of the respondents choose very good, whereas two of the respondents choose excellent for this question. This shows that the overall system functionality is very smooth.

Table $\mathrm{X}$ shows the usability testing questions, comprising of Question 7 to Question 12. Meanwhile, Fig. 16 shows the result of the usability testing from questionnaire filled by four multimedia experts from UTeM.

\section{TABLE X. USABILITY TESTING QUESTION}

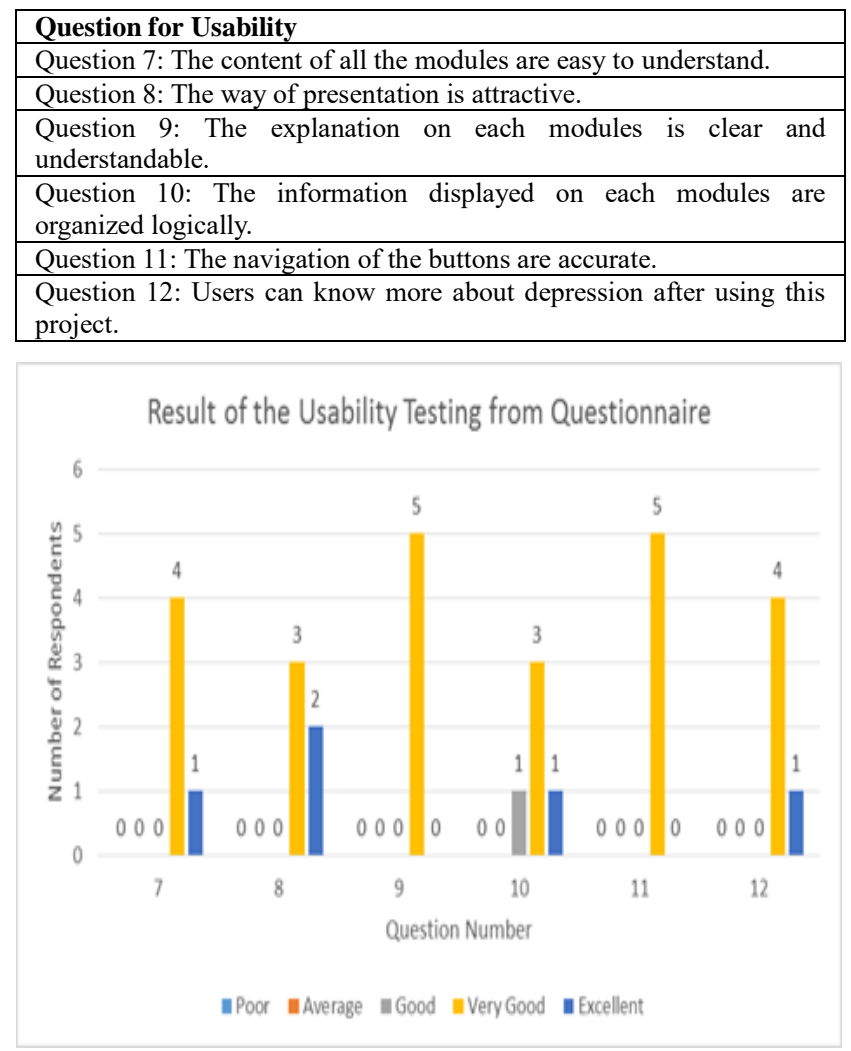

Fig. 16. Result of Usability Testing from Questionnaire

Fig. 16 shows that for Question 7 related to the understanding level of the content, there are four of the respondents choose very good for this question whereas one of the respondents chooses excellent as they think that the content of all modules are very easy to understand. Meanwhile, For Question 8, two out of 5 respondents choose excellent as their answer whereas 3 out of 5 respondents choose very good as their answer to the question about the way of presentation which is very attractive. For the next question, which asking about the explanation on each modules, it shows that all of the respondents choose very good as their option. This is because the explanation on each modules is very clear and understandable for users. Most of the respondents choose very good as their answer whereas one of the respondents chooses excellent as his or her answer for Question 10. They think that the information displayed on each modules are organized logically. Only one of the respondents choose neutral for this question as he or she thinks that the information displayed on each modules can be organized more logically. All of the respondents choose very good for Question 11. They think that the navigation of the buttons are very accurate. Finally, for Question 12, four out of 5 respondents choose very good as 
their option for this question, whereas one out of 5 respondents chooses excellent as their option. This shows that users able to know more about depression after using this project.

The testing questions for multimedia experts focusing on the third part, which is the user interface is presented in Table XI. Meanwhile the result of these questios can be referred in Fig. 17.

TABLE XI. USER INTERFACE TESTING QUESTION

\begin{tabular}{|l|}
\hline Question for Usability \\
\hline $\begin{array}{l}\text { Question 13: Animation of this project attracts users to know more } \\
\text { about the information. }\end{array}$ \\
\hline Question 14: The texts in this 2D animation are readable. \\
\hline Question 15: The colour used in this 2D animation is suitable. \\
\hline Question 16: The video is presented clearly. \\
\hline $\begin{array}{l}\text { Question 17: The audio is clear and helps the users understand more } \\
\text { on the modules. }\end{array}$ \\
\hline Question 18: The graphics are clear and suitable. \\
\hline
\end{tabular}

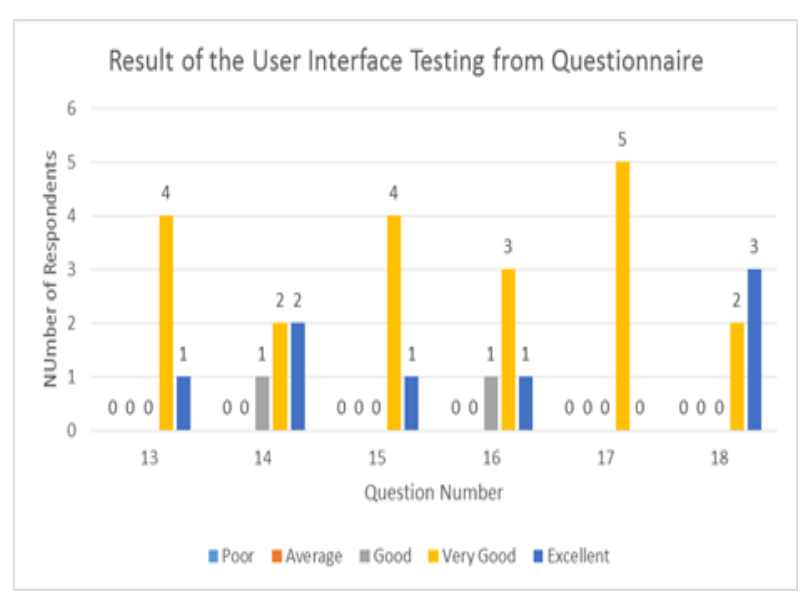

Fig. 17. Result of User Interface Testing from Questionnaire

Based on Fig. 17 which filled by four multimedia experts, it shows that for Question 13 which related to the animation, most of the respondents choose very good as their option, whereas one of the respondents chooses excellent as their option. Overall, the animation of this project attracts users to know more about the information well. Two out of 5 respondents choose very good for Question 14, whereas another 2 out of 5 respondents choose excellent for this question. Only one respondent chooses neutral for this question. For respondents that choose excellent and very good as their option, they agree that the text used in this $2 \mathrm{D}$ animation are readable. Only one of the respondents thinks that the text readability can be improved. For Question 15 which asking about the colour used in this animation, majority of the respondents choose very good for this question. Only one respondent chooses excellent for this question. This shows that the colour used in this $2 \mathrm{D}$ animation is very suitable. For the next question about the video, three out of 5 respondents choose very good as their option. Meanwhile, two respondents chooses excellent and neutral as their option, respectively.
Most of the respondents think that the video is presented clearly, whereas one of the respondents think that the video can be presented more clearly. All of the respondents choose very good for the second last user interface testing question. It is claimed that the audio is very clear and helps users understand more on the modules. For Question 18 which about the graphics used, majority of the respondents choose excellent as their answer whereas minority of the respondents choose very good option. This shows that the graphics used in this project are very clear and suitable.

\section{3) Test Result for Tertiary Students}

There are 70 respondents that participate in this testing. Most of the respondents are third year undergraduate students aged from 20-25 years old. For the tertiary students testing, it involved an equal percentage of male and female which are $50 \%$ (35 respondents) respectively. Meanwhile, majority of the respondents age from 20 to 25 years old which is $73 \%$ (51 respondents) whereas minority of respondents aged from 26 to 30 years old which is $4 \%$ (3 respondents). There is $23 \%$ (16 respondents) of respondents aged from 15 to 20 years old, which is the second highest among other ages. Chinese is the highest ethnicity among other ethnicities which is 57\% (40 respondents). The second highest ethnicity is Malay which consists of $37 \%$ (26 respondents). Lastly, only 6\% (4 respondents) of respondents are Indian, which is the lowest ethnicity.

Majority of the respondents are in their third year of study which is $50 \%$ (35 respondents), whereas minority of the respondents are in their second and fifth year of study which are $14 \%$ (10 respondents) respectively. In addition, most of the respondents are undergraduate students which consists of $63 \%$ (44 respondents) whereas least of the respondents are postgraduate students which consists of $7 \%$ (5 respondents) only.

Table XII shows the first five questions prepared for the tertiary students. Fig. 18 shows the test result for tertiary students from Question 1 to Question 5.

TABLE XII. TESTING QUESTION FOR TERTIARY STUDENTS (QUESTION 1QUESTION 5)

\begin{tabular}{|l|}
\hline Question for Tertiary Students \\
\hline $\begin{array}{l}\text { Question 1: Do you know more about definition, statistics, types, } \\
\text { symptoms, causes and treatments of depression among tertiary } \\
\text { students through this 2D animation? }\end{array}$ \\
\hline $\begin{array}{l}\text { Question 2: Do you know more about common causes and way to } \\
\text { overcome depression through interview video of this 2D animation? }\end{array}$ \\
\hline $\begin{array}{l}\text { Question 3: Do you understand all the explanation of the seven (7) } \\
\text { modules presented from this 2D animation? }\end{array}$ \\
\hline $\begin{array}{l}\text { Question 4: Does this 2D animation raise your awareness towards } \\
\text { depression? If No, please specify why. }\end{array}$ \\
\hline $\begin{array}{l}\text { Question 5: Do you think you can apply the knowledge of depression } \\
\text { to help those (family, friends, and so on) who suffer from it? If No, } \\
\text { please specify why. }\end{array}$ \\
\hline
\end{tabular}




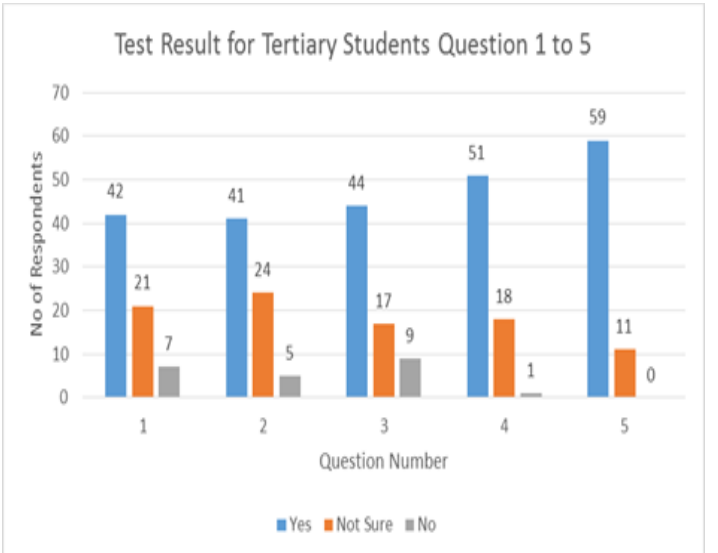

Fig. 18. Test Result for Tertiary Students Question 1 to Question 5

Most of the respondents choose Yes as their answer for Question 1 to Question 5 which are 42 respondents, 41 respondents, 44 respondents, 51 respondents and 59 respondents, respectively. After using this project, majority of the respondents know more about the definition, statistics, types, symptoms, causes and treatments of depression among tertiary students for Question 1 and they also know more about common causes and way to overcome depression through interview video for Question 2. Furthermore, all explanation of seven modules presented in 2D animation are understood by most of the respondents for Question 3 and depression awareness among respondents are raised for Question 4. Knowledge of depression can be applied by most of the respondents in helping those who depressed for Question 5. Only minority of respondents choose No as their answer which are 7 respondents, 5 respondents, 9 respondents and 1 respondent for Question 1, Question 2, Question 3 and Question 4, respectively. They think that there might be improvement to be made for Question 1 to Question 4.

TABLE XIII. TESTING QUESTION FOR TERTIARY STUDENTS (QUESTION 6QUESTION 10)

\begin{tabular}{l}
\hline Question for Tertiary Students \\
\hline $\begin{array}{l}\text { Question 6: Does the 2D animation is attractive and easy to } \\
\text { understand? If No, please specify why. }\end{array}$ \\
\hline Question 7: The text in this 2D animation is readable. \\
Question 8: The voice of narrator is clear and understandable. \\
\hline $\begin{array}{l}\text { Question 9: The interview video about common depression questions } \\
\text { is clear and understandable. }\end{array}$ \\
\hline $\begin{array}{l}\text { Question 10: Do you feel enjoyed and satisfied when using this } \\
\text { application? }\end{array}$ \\
\hline
\end{tabular}

Table XIII shows the other five questions for the tertiary students and Fig. 19 shows test result answered by 70 respondents who are tertiary students for Question 6 to Question 10.

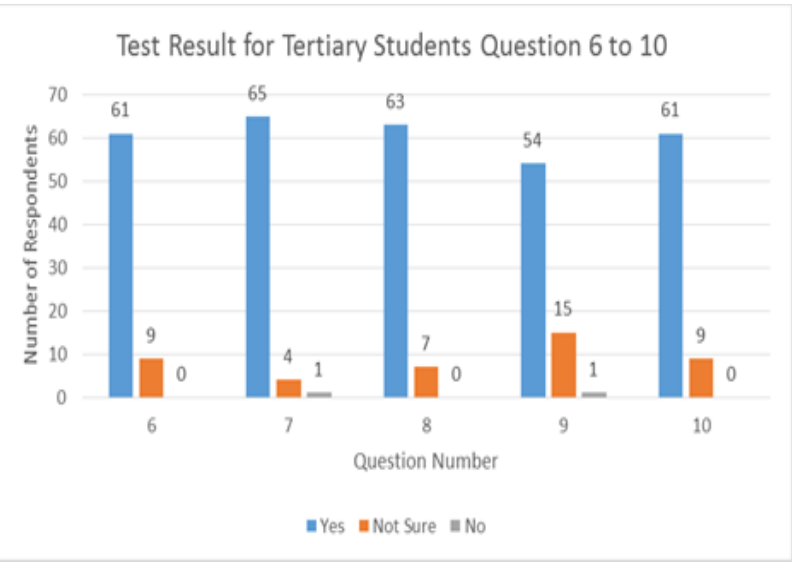

Fig. 19. Test Result for Tertiary Students Question 6 to Question 10

Based on Fig. 19, it can be seen that 61 out of 70 respondents agree that the $2 \mathrm{D}$ animation is attractive and easy to understand, whereas 65 out of 70 respondents agree that the text in this $2 \mathrm{D}$ animation is readable. This is because this $2 \mathrm{D}$ animation is attractive and understandable and the text is readable for users. For Question 8 to Question 10, majority of the respondents choose Yes as their option which are 63 respondents, 54 respondents and 61 respondents, respectively. This shows that respondents think the voice of narrator and interview video about common depression questions are clear and understandable for Question 8 and Question 9. Moreover, most of respondents feel very enjoy and satisfied when using this application. In contrast, only one respondent chooses No as his or her answer for Question 7 and it same goes to Question 9. They may think that the text and interview video in this project can be improved.

Based on the test result analysis gathered from three categories of respondents, it can be concluded that the 2D animation received a good feedback and suggestions. The 2D animation is strongly accepted to be used as a medium to give the depression information and raise depression awareness to its users.

\section{DISCUSSION}

In the development of the project, the strengths and weaknesses were discovered by gathering all the test result analysis. This project is attractive as it consists of many multimedia elements and interactive buttons, which able to attract the user attention. In addition, the characters of the animation are well designed for presenting the depression information. Besides, the flow or movement of the animation are nice and smooth. In addition, the procedure of the project is designed nicely to make it ease of use for the users. The users can easily understand the information presented. The most important thing is the information presented is clear and accurate since it is verified by the Subject Matter Expert which is the counsellor. 
However, this project is lack of activity modules. By adding activity modules such as quiz or games, users can interact more with the application and their understanding towards depression can be increased. Moreover, users can easily understand every modules if the explanation of each modules is simple and understandable. Improved quality of the video interview also can give a pleasant and nice view for the users. Therefore, users can easily concentrate on the content of the video. In addition, users can be more enjoyed and pleased by using $3 \mathrm{D}$ animation to have a more attractive view that $2 \mathrm{D}$ animation.

\section{CONCLUSION}

In conclusion, the 2D animation has developed successfully. The objectives have been achieved where the interactive content development provides the complete depression information to the public. It is envisaged that the developed interactive content would greatly contribute to increase the understanding and awareness to the public especially tertiary students. It is hoped that the developed application will assist the counsellor, parents and community in delivering the depression information efficiently.

This project contributes to public, especially tertiary students by increasing their understanding and awareness on depression. Depression among students can be identified and proper treatments can be provided. Furthermore, help and encouragement can be offered to tertiary students' family or friends who are depressed. This project also contributes to UTeM Counselling Unit and any university and college counselling unit for future use.

\section{ACKNOWLEDGMENT}

This project is part of Final Year Project of Faculty of Information and Communication Technology, Universiti Teknikal Malaysia Melaka. This project won Silver Medal at the e-Learning Carnival \& Conference 2018 (eLCC 2018) organized by Centre for Instructional Resources \& Technology (PSTP), Universiti Teknikal Malaysia Melaka.

The authors are thankful to the Counsellor from UTeM Counselling Unit for providing the information and involvement in the testing phase. In addition, the deepest gratitude and thanks go to the lecturers from the Department of Interactive Media, Faculty of Information and Communication Technology, UTeM for their expertise during the testing evaluation of the product.

\section{REFERENCES}

[1] D. J. Kirsch, L. A. Doerfler, M.A. Truong, "Mental health issues among college students: who gets referred for psychopharmacology evaluation?", Journal of American College Health vol. 63 no. 1, pp. 5056, 2015.

[2] Institute for Public Health (IPH), "National Health and Morbidity Survey 2015 (NHMS 2015)", Non-Communicable Diseases, Risk Factors \& Other Health Problems, vol. 2, 2015.

[3] N. Ibrahim, S. Mohd Sidik, C.K. Phang, F. Mukhtar, H. Awang, J. K. Ang, Z. L. Osman and S.F.A Ghaffar, "Prevalence and predictors of depression and suicidal ideation among adolescents attending government secondary schools in Malaysia”. Med Malaysia vol. 72 no.4, pp. 222-227, 2017.

[4] American Psychiatric Association, 2018, What is Depression?, available online: https://www.psychiatry.org/patients-families/ depression/whatis-depression, last visit:09.03.2018

[5] World Health Organization, 2017, Depression: let's talk. available online:http://www.who.int/mentalhealth/management/depression/en, last visit:06.03.2018

[6] The Star Online, 2017, Depression: 40\% of Malaysians will suffer from mental health issues in their lifetime, available online: https://www.thestar.com.my/news/nation/2017/04/02/malaysians-willsuffer-from-mental-health-issues-in-their-lifetime/, last visit:06.03.2018

[7] World Health Organization, 2017, Depression, available online: http://www.who.int/mediacentre/factsheets/fs369/en/, visit:08.03.2018

[8] The Sun Daily, 2016, Mental health of Malaysian students worrisome, available online: http://www.thesundaily.my/news/1967970, last visit: 10.03.2018

[9] N. Kumaraswamy, "Academic Stress, Anxiety and Depression among College Students- A Brief Review". International Review of Social Sciences and Humanities vol. 5, no.1, pp. 135-143, 2013

[10] T. M. Khan, S. A. Sulaiman and M. A. Hassali, "Mental health literacy towards depression among non-medical students at a Malaysian university", Mental Health in Family Medicine vol.7, no. 1, pp. 27-35, 2010

[11] Y. Nam, J. M. Bertolote, B. H Chia, T. Maniam, M. R. Phillips, J. Pirkis, and H. Hendin, "Creating Public Awareness in Asia of Depression as Treatable and Suicide as Preventable", Suicide and Suicide Prrevention in Asia, pp. 31-38, 2008

[12] India Education, What is Animation, available online: http://www.indiaeducation.net/animation/what-is-animation.html, last visit:11.03.2018

[13] R. Rosdin, Depression motion graphic awareness campaign, available online: https://www.youtube.com/watch?v=9SY hO ED iIVA\&t=3s, last visit:14.03.2018

[14] IRDResearch, Depression \& Anxiety Awareness video- English, available online: https://www.youtube.com/watch?v= 2s8PYL Mp7RQ, last visit: 14.03 .2018

[15] TED-Ed, What is depression? - Helen M. Farrell available online:https://www.youtube.com/watch?v=z-IR48Mb3W0, last visit: 14.03.2018 